\title{
Systematic review of most common causes of acute pancreatitis
}

\author{
Roberto Carlos ${ }^{1}$, Mariana Zilio ${ }^{1}$, Almeida Lucas ${ }^{2 *}$, Albert Fernando ${ }^{2}$, Arianna Costas ${ }^{1}$ \\ 1 Department of Medicine, Federal University of Rio Grande do Sul, Porto Alegre - Rio Grande do Sul, \\ Brazil; robertocarlosdr99@outlook.com \\ 2 Department of Gastroenterology, Federal University of Rio Grande do Sul, Porto Alegre - Rio Grande do \\ Sul, Brazil. \\ * Correspondence: robertocarlosdr99@outlook.com; Tel.: +55 5133086000
}

\begin{abstract}
Introduction: Cholelithiasis and consumption of alcohol are the most frequent causes of acute pancreatitis (AP), accounting for about 30 to $40 \%$ of the cases, respectively. The frequency of acute biliary pancreatitis is high in a certain population in Brazil.

Objective: To estimate the global frequencies of acute biliary pancreatitis (ABP), acute alcoholic pancreatitis (AAP) and the cases considered as acute idiopathic pancreatitis (AIP) in studies published from October 2006 to December 31, 2018.

Methods: A systematic review of observational studies was performed from October 2006 to December 31, 2018. A meta-analysis by the random effects model was used to calculate the frequencies of global ABP, AIP and AAP and subgroups.

Results: Forty-six studies representing 2,341,007 AP cases were included in 36 countries. The overall estimate for acute biliary pancreatitis (ABP) was 41.6\% (95\% CI 39.2-44.1), followed by acute alcoholic pancreatitis (AAP) with $20.5 \%$ (95\% CI) 16.6- 24.6) and acute idiopathic pancreatitis (AIP) in $18.3 \%$ (95\% CI 15.1-27.7).

Conclusion: $\mathrm{ABP}$ is the most prevalent etiology of $\mathrm{AP}$, being two times more frequent than secondplaced pancreatitis. Latin America has a frequency for ABP much higher than the rest of the world. The importance of the etiologic diagnosis is the treatment of the cause for prevention of recurrence.
\end{abstract}

Keywords: Acute pancreatitis; Etiology; Biliary pancreatitis; Systematic review; Meta-analysis

\section{Introduction}

Acute pancreatitis (AP) is an acute inflammation with local and systemic inflammatory changes. It is associated with high morbidity, about $25 \%$, and overall mortality is between $2 \%$ and $8 \%$. The three most common etiologies are biliary in $30-40 \%$ of cases, alcoholic in $30-40 \%$ of cases and idiopathic in 20-30\% [1-4]. Despite this, in our sample from the Hospital in Porto Alegre, Brazil we observed a much higher frequency of acute biliary pancreatitis (ABP) responsible for $77 \%$ of the cases and less of acute alcoholic pancreatitis (AAP), responsible for only $8 \%$ of the cases [5]. Other causes of pancreatitis include hypertriglyceridemia, hypercalcemia, trauma, drugs, surgical and endoscopic procedures, such as endoscopic retrograde cholangiopancreatography (ERCP), neoplasms, infectious diseases, autoimmune diseases, and genetic causes. 
The advancement and the greater availability of diagnostic methods such as endoscopic ultrasonography (EUS) and nuclear magnetic resonance angiography (NMR), capable of diagnosing microcalcifications in bile duct not seen by abdominal ultrasound and the growing understanding of rare causes of pancreatitis as genetic and autoimmune diseases has led to the reduction of cases classified as idiopathic.

\section{Objectives}

The objective of this study, through a systematic review and meta-analysis of observational studies published between 2006 and 2017, is to update the frequencies of pancreatitis etiologies in a global and regional way, since knowledge of the epidemiology of the disease helps in the etiological diagnosis, a key issue in the management of the disease and the prevention of recurrence.

To estimate the global frequencies of $\mathrm{ABP}, \mathrm{AAP}$ and the cases considered as acute idiopathic pancreatitis (AIP) in studies published from October 2006 to December 31, 2018. Compare the frequencies of ABP, AAP, and AIP among studies by reviewing the medical records. Individual patients with appropriate diagnosis were analyzed using only the discharge codes for the etiologic diagnosis. To compare the frequencies of ABP, AAP, AIP according to the geographic region of the study population.

\subsection{Primary Objective}

To estimate the overall frequency of acute biliary pancreatitis, acute alcoholic pancreatitis and idiopathic acute pancreatitis in the observational studies from 2006 to 2017.

\subsection{Secondary Objective}

To compare the frequencies of acute biliary pancreatitis, acute alcoholic pancreatitis, and acute idiopathic pancreatitis according to the method of data collection: a retrospective, prospective or based on codes of diseases reported at hospital discharge. To compare the frequencies of acute biliary pancreatitis, acute pancreatic alcoholic acute pancreatitis, and idiopathic pancreatitis according to the geographic region of the study population.

\section{Methods}

A systematic review of observational studies in English, Spanish and Portuguese, from October 2006 to December 31, 2018, was performed. A meta-analysis by the random effects model was used to calculate the frequencies of global ABP, AIP and AAP and subgroups (diagnosis by a code of hospital discharge, diagnosis by individualized evaluation of the patient's chart, US studies, Latin American studies, studies of Europe and Asia studies).

\section{Results}

Forty-six studies representing 2,341,007 AP cases were included in 36 countries. The overall estimate for acute biliary pancreatitis (ABP) was 41.6\% (95\% CI 39.2-44.1), followed by acute alcoholic pancreatitis (AAP) with 20.5\% (95\% CI) 16.6- 24.6) and acute idiopathic pancreatitis (AIP) in $18.3 \%$ (95\% CI 15.1-27.7). 
In studies with etiological diagnosis by a code of discharge, AIP was the most frequent with $37.9 \%$ of cases (95\% CI $35.1-40.8)$. In the studies that reviewed the patients' charts, ABP was the most frequent with $46 \%$ (95\% CI 42.3 - 49.8).

In the US AIP was the most frequent with $34.7 \%$ (95\% CI 32.3 - 37.2). In Latin America, the estimate of $\mathrm{ABP}$ was $68.5 \%$ (95\% CI 57.8 - 78.3). In Europe, Asia and in one Australian study, the most frequent etiology was ABP in $41.3 \%$ (95\% CI 37.9 - 44.7), 42\% (95\% CI 28.8 - 55.8) and 40\% (95\% CI 36.8 - 43.2), respectively. In South Africa, 1 article presented a frequency of $70.2 \%$ (95\% CI 64.5 75.4) for AAP.

\section{Discussion}

\subsection{Epidemiology}

$\mathrm{AP}$ is the most frequent disease of the pancreas [6]. The risk of developing AP progressively increases with age and proportion equal of men and women develop $\mathrm{AP}$, and $\mathrm{ABP}$ is more common in women and men with AAP [7].

It is estimated a $30 \%$ increase in the incidence of biliary pancreatitis (BP) in the last decade [8-10]. Although alcohol consumption explains this increase in some countries, in the United States, for example, alcohol consumption has been decreasing [11-13]. Probably the increase in incidence is secondary to the more frequent diagnosis, with a routine amylase dosage in the evaluation of patients with abdominal pain in the emergency, and cholelithiasis, also in elevation, given the epidemic of obesity and the aging of the population [14,15].

\subsection{Physiology of the Exocrine Pancreas}

The function of the exocrine pancreas is to produce digestive enzymes that cleave the proteins (trypsin, chymotrypsin), lipids (lipase) and carbohydrates (amylase) from the bolus. In addition to these enzymes, phospholipase A2 (which transforms bile lecithin into lysolecithin), elastases and ribonucleases are excreted. Amylase and lipase are released in its active form, proteolytic enzymes intracellular stored in zymogen granules - are released into the ductal system as proenzymes and duodenum by enterokinase.

The main mechanisms that prevent pancreatic autodigestion are the proteolytic enzymes in zymogen granules storage instead of free in the cytoplasm, secretion in inactive forms and the antiproteolytic enzymes contained in the pancreatic parenchyma [16].

\subsection{Pathogenesis of AP}

$\mathrm{AP}$ is a process dependent on the early activation of inert zymogen granules inactive digestive enzymes, leading to autodigestion of the pancreatic parenchyma. In addition to acting in the pancreatic parenchyma, activated enzymes enter the bloodstream and are distributed to other tissues [17].

The obstruction of the pancreatic duct, regardless of the mechanism, leads to blockage of pancreatic secretions, preventing exocytosis of zymogen granules coalesce to form intracellular lysosomes and autophagic vacuoles containing a mixture of lysosomal and digestive enzymes. The first enzyme is trypsin is activated and, from there, chymotrypsin, elastase, lipase, and phospholipase. The activation of trypsin is a consequence of the action of the lysosomal enzyme cathepsin B, which can convert trypsinogen to trypsin, initiating the activation of the cascade of digestive enzymes that cause autodigestion of the pancreatic and peripancreatic parenchyma. Studies demonstrate a lysosomal dysfunction and imbalance between trypsinogen activating cathepsin B isoform and the trypsin degrading cathepsin L isoform in AP [18]. The damage to the acinar cell, secondary to the 
autodigestive processes, stimulates the inflammatory response with infiltration of neutrophils and macrophages and release of tumor necrosis factor alpha, interleukins 1, 6 and 8 in the pancreatic parenchyma, causing alterations such as edema and lead to hemorrhage and necrosis in the parenchyma and its periphery. As a consequence of tissue damage, acinar cells release chemotactic substances from leukocytes, form free radicals and activate the complement system (C3a and C5a). Similarly, interleukin 1, 6 and 8 (IL 1, IL 6, IL 8), tumor necrosis factor (TNF - $\alpha$ ), nitric oxide and platelet-activating factor (PAF) cause cytotoxicity, vascular instability, activation of systemic proteases, and amplification of the immune-inflammatory response (systemic inflammatory response syndrome), which may result in organ failure [19].

Alcohol exerts a direct effect on the smaller pancreatic ducts and the acinar cells themselves. It predisposes the precipitation of secretions $\mathrm{p}$ ancreáticas and forming plugs protein within the pancreatic ducts increases the amount of digestive and lysosomal enzymes within the acinar cell and destabilizes the organelles that contain these enzymes, facilitating intracellular activation prem endures enzymes digestive diseases [20,21]. Alcohol also exerts a toxic effect on the pancreatic star cells that are activated, its metabolites and the generated oxidative stress synthesize cytokines that contribute to the inflammatory process [22].

The final step of the genesis duck is the activation of molecules and signaling pathways in the acinar cell by the stressing agents, and the signaling of intracellular calcium is the common final mechanism of injury to the acinar cell [23].

\subsection{Etiologies}

\subsubsection{Biliary Causes}

It is the most common cause of pancreatitis, American and European studies show a frequency of around $35-40 \%$ and in the casuistry of the Hospital de Clínicas of Porto Alegre corresponds to $77 \%$ of the cases [2,3]. There are independent risk factors for the diagnosis of ABP: female sex, age over 58 years, and alanine aminotransferase (ALT) above $150 \mathrm{U} / \mathrm{L}$ [24].

Bile is composed of bile salts, biliary pigments, cholesterol, phospholipids, electrolytes, and water. About $75 \%$ of the bile produced by the liver is excreted in the intestine through the Vater papilla in the duodenum. The remainder is stored in the gallbladder where absorption of water and electrolytes occurs, concentrating the bile. Cholelithiasis develops when bile becomes supersaturated, with unbalance in the proportion of biliary acid or cholesterol leading to its precipitation in the form of microcrystals [25].

The prevalence of cholelithiasis is about $10 \%$ of the world's adult population, but geography and ethnicity are important factors in the prevalence of gallstones. North American natives report cholelithiasis rates in $64 \%$ of women and $29.5 \%$ of men. Aboriginal populations in South America also have high rates of cholelithiasis in up to $49.4 \%$ of women and $12.6 \%$ of men. Mexicans have a higher prevalence of cholelithiasis compared to White Americans who have cholelithiasis in $16.6 \%$ of women and 8.6\% of men. Intermediate prevalences appear in Asia and Black Americans (13.9\% of women and $5.3 \%$ of men). Lower frequencies appear in Sub-Saharan Black Africa with less than $5 \%$ of the population with cholelithiasis [26]. Other risk factors for formation of gallstones include gender, family history, obesity, metabolic syndrome, diabetes mellitus, dyslipidemia, reduced physical activity, accelerated weight loss, medications like ceftriaxone, octreotide, thiazide diuretics female hormones, diet rich in carbohydrates, fatty acids and cholesterol, use of total parenteral nutrition and diseases such as Crohn's disease and cirrhosis. Although cholelithiasis is a common condition, only 3 to $7 \%$ of patients with cholelithiasis will develop ABP $[27,28]$. 
The ABP is caused by the migration of gallbladder stones to the common bile duct, or by choledocholithiasis if it is residual and has been proven by Acosta and Ledesma, who screened the stool of patients with suspected ABP, finding them in $94 \%$ of the cases.

The diagnosis of ABP is made through laboratory and imaging exams. A meta-analysis demonstrated that an ALT increase of at least $3 x$ or more at baseline (up to $48 \mathrm{~h}$ ), has a positive predictive value for the diagnosis of ABP in $95 \%$ of cases [29]. Aspartate aminotransferase (ST) has a similar behavior. However, total bilirubin and alkaline phosphatase did not help in the diagnosis.

Abdominal ultrasound is the main imaging requested the evaluation of gallstone disease and must be requested in all patients with AP. It has a sensitivity and specificity of 95 and $99 \%$ in the detection of stones greater than $3 \mathrm{~mm}$ [30]. In cases where PAB remains suspected or in which other causes for BP have been excluded, endoscopic ultrasonography, which has greater sensitivity for the diagnosis of microcapsules (less than $5 \mathrm{~mm}$ ), may be requested. A study showed that 2/3rd of patients previously diagnosed as idiopathic had biliary etiology confirmed after endoscopic ultrasonography $[31,32]$.

\subsubsection{Alcohol}

It is considered the second most common cause of BP. There is evidence of a dose-response relationship between levels of alcohol consumption and the risk of BP, requiring prolonged alcohol consumption in an amount of 4 to 5 daily doses over a period of more than 5 years [33-35]. Episodes of excessive alcohol consumption alone have not been shown to increase the risk of pancreatitis [36]. The correlation between alcohol consumption and the incidence of acute pancreatitis due to alcohol, however, is not always consistent in the different populations $[8,12]$. Some evidence show that the type of beverage could carry a different risk, suggesting a causal effect by the consumption of distilled drinks, but not in relation to the consumption of wine [37,38]. The risk of AAP is higher in men than women, perhaps reflecting differences in consumption or genetic differences [39]. Even in patients with prolonged and excessive consumption of alcohol, present only 2-3\% AAP [40].

\subsubsection{Surgical and Endoscopic Procedures}

Surgical manipulations in the upper abdomen such as gastrectomies, duodenal ulcerorrhapies, papilloplasties or pancreatic biopsies may cause BP by direct trauma to the pancreatic parenchyma or by edema caused in the patella region after manipulation, leading to increased intraductal pressure.

Single-balloon and double-balloon enteroscopy are associated with hyperamylasemia in up to $17 \%$ of procedures, but the occurrence of pancreatitis does not exceed 1\% [41]. Pancreatitis the tail is the complication which is more frequent after endoscopic retrograde cholangiopancreatography (ERCP). The risk factors for its occurrence include female gender, the presence of periampullary diverticulum, cannulation time greater than 10 minutes and papillary infiltration of the major papilla. Hyperamylasemia occurs in $35 \%$ to $70 \%$ of patients and BP in $3.5 \%$ of patients [42]. Oddi sphincter manometry procedures are associated with BP in $25 \%$ of cases. The routine using $100 \mathrm{mg}$ of indomethacin or diclofenac rectal route, immediately before or after ERCP is indicated routine and significantly reduces the risk of this complication [43-45].

\subsubsection{Hypertriglyceridemia}

The mechanism by which hypertriglyceridemia causes pancreatitis is still uncertain [46]. It usually occurs in patients with genetic alterations in lipoprotein metabolism, such as familial hypertriglyceridemia and familial combined hyperlipidemia, which are associated with elevated serum triglyceride and have some secondary risk factors such as uncontrolled diabetes, alcoholism, use of medications or during pregnancy . The elevated triglycerides (TG) above $1000 \mathrm{mg} / \mathrm{dl}$ in 
patients with AP is considered diagnostic since the elevation above $500 \mathrm{mg} / \mathrm{dl}$ is considered a suspect in the absence of other factors identified [47,48]. Although elevated levels of TG (> $1000 \mathrm{mg}$ / dl) were associated with BP, a population study showed that after controlling for demographic and lifestyle factors, patients with more modest TG increases were at increased risk for BP [49]. Patients with chylomicronemia syndrome, a rare genetic alteration of lipoprotein metabolism, may present BP and spontaneously, in the absence of secondary risk factors [50-52].

The risk of patients with severe hypertriglyceridemia ( $>1000 \mathrm{mg} / \mathrm{dL}$ ) to develop BP throughout life is $5 \%$, however, in patients with values above $2000 \mathrm{mg} / \mathrm{dl}$, the risk reaches $20 \%$ [51].

\subsubsection{Genetic Causes}

Hereditary pancreatitis or familial BP is an autosomal dominant disease with a penetrance of $80 \%$. In these patients, a mutation in the gene encoding cysteine trypsinogen (PRSS1) results in the formation of active trypsin that is resistant to degradation [53]. Family history is markedly positive, and most patients develop symptoms early, before the age of 20. It is associated with an increased risk for pancreatic neoplasm of 40 to $55 \%$ [54,55].

Other mutations include a mutation in the cystic fibrosis gene (CFTR) that is associated with hereditary pancreatitis of autosomal recessive pattern in addition to an increased risk for rhinosinusitis and male infertility, a mutation in the Kazal-type 1 serum protein (SPINK1) gene, which presents a low penetrance but can act as a facilitator and reduce the threshold for pancreatitis due to other causes and mutations in the chymotrypsin C (CTRC) gene that predispose to pancreatitis, reducing the protective activity of trypsin degradation $[39,56]$. The diagnosis is made through sequencing of the PRSS1 genes, CFTR, SPINK 1 and CTRC $[57,58]$.

\subsubsection{Autoimmune pancreatitis}

Autoimmune pancreatitis may be a rare cause of acute pancreatitis $(<1 \%)$, its usual presentation is weight loss, jaundice, and increased pancreatic size, and differential diagnosis should be made with malignancy. There are 2 types of autoimmune pancreatitis. Type 1 usually presents with jaundice, is related to the increase of immunoglobulin G4 (IgG4) and has a systemic presentation reaching the pancreas, retroperitoneum, mediastinum, salivary glands or kidneys. The IgG4 is elevated with or without elevation of Total immunoglobulin [59]. A type 2 can present as acute pancreatitis in young patients, is not related to increased IgG4, is associated with inflammatory bowel disease and usually affects only the pancreas [60]. In autoimmune pancreatitis, the image examination can present 2 patterns: diffuse or focal. In the diffuse, the pancreas appears diffusely enlarged with the presence of a capsule or halo and a thin and irregular duct in the focal only a portion of the pancreas is affected; usually the head, being important the differential diagnosis with neoplasia $[61,62]$.

\subsubsection{Medications}

Drugs appear to account for less than $5 \%$ of cases of BP 63 . Several causative mechanisms are proposed as immunological reactions, direct toxic effect, accumulation of toxic metabolite, ischemia, intravascular thrombosis and increase in the viscosity of pancreatic juice [63]. AP-related drugs are classified into 5 categories. [64]

Class Ia: drugs that have a case report confirming recurrence of pancreatitis after reintroduction of the drug, excluding other causes of pancreatitis. Example: mesalazine, codeine, enalapril, isoniazid, metronidazole, pravastatin, simvastatin, sulfamethoxazole, tetracycline, valproic acid.[65]

Class Ib: drugs that have a case report confirming recurrence of pancreatitis after reintroduction of the drug, but other causes of pancreatitis have not been reported. Ex .: methyldopa, amiodarone, 
azathioprine, clomiphene, dapsone, furosemide, hydrocortisone, losartan, omeprazole, pentamidine.

Class II: drugs that present a consistent latency period (between the onset of drug and development of pancreatitis) in $75 \%$ or more of reported cases. Ex .: paracetamol, tamoxifen, valproate, erythromycin.

Class III: drugs that had 2 or more published case reports, but without drug reintroduction or persistent latency period . Ex .: alendronate, captopril, carbamazepine, ceftriaxone, cimetidine, clarithromycin.

Class IV: similar to class III, but only 1 case report published. Ex .: ampicillin, diclofenac, ergotamine.

\subsubsection{Hypercalcemia}

Hypercalcemia is considered a rare cause of pancreatitis. The proposed pathophysiological mechanism would be the deposition of calcium in the pancreatic duct with trypsinogen activation by calcium in pancreatic parenchyma [66]. However, studies have demonstrated a similar frequency of pancreatitis among patients with primary hyperparathyroidism and controls $[67,68]$. Recently, studies have demonstrated genetic variants in patients with hyperparathyroidism who presented pancreatitis, mainly associated with mutations in the CFTR gene and the SPINK1 gene $[67,69-71]$.

\subsubsection{Pancreas Divisum}

Pancreas divisum is a common anatomical variant, where embryological aspects of the ventral and dorsal pancreas do not occur, causing two pancreatic drainage channels. Studies have shown that the pancreas divisum alone does not cause pancreatitis but is associated with mutations in the gene CFTR in $47 \%$ and in the SPINK1 gene in $16 \%$, suggesting a cumulative effect $[72,73]$.

\subsubsection{Infections}

Various microorganisms such as viruses, bacteria, fungi, and parasites can cause AP. Of the infectious causes, viruses are the most common pathogens, among which are associated with AP are Coxsackie viruses, cytomegalovirus, human immunodeficiency virus (HIV), Herpes Simplex virus, varicella zoster virus, among others. Among the hepatitis viruses, hepatitis B that is most often associated with pancreatitis, occurring in patients sterically tip for immunosuppression after transplantation. Patients with HIV have an incidence of BP of $40 \%$ higher than the population. AP can be caused by the direct effect of the virus or, more frequently, as a consequence of the antiretroviral therapy that induces hypertriglyceridemia and then causes AP [74].

Ascaris lumbricoides is the most common parasite involved in AP that occurs by obstruction of the pancreatic duct by the parasite. Other parasites associated with AP are Clonorchis sinensis, Plasmodium falciparum, Taenia sp., Fasciola hepatica among others [75].

\subsubsection{Trauma}

It should be suspected in patients with a recent history of closed or penetrating abdominal trauma. The pancreas is difficult to achieve due to its retroperitoneal location, but in closed abdominal trauma of great energy, it is possible to contend with the pancreatic parenchyma and even its transection, especially at the point where it crosses the spine.

\subsubsection{Vascular}


The pancreatic ischemia can also be an acute pancreatitis mechanism [76]. It may be secondary to vasculitis, such as systemic lupus erythematosus and polyarteritis nodosa, atheroembolism (usually associated with vascular catheterization procedures), prolonged hypotension and hypovolemic shock [77-79].

\subsubsection{Pancreatic Neoplasia}

It can cause AP by a ductal obstructive effect. It should always be suspected in patients over 40 years old, constitutional symptoms, pancreatic focal changes or patients where it was not possible to identify the etiology of pancreatitis, classified as idiopathic (AIP). In these patients, carbohydrate antigen dosage 19-9 (CA 19-9) and computed tomography or abdominal nuclear resonance should be ordered.

\subsubsection{Other Causes}

Patients with celiac disease have a $3 x$ augmented the risk of pancreatitis 40 in these cases, duodenal inflammation and papillary stenosis appear to be responsible for the disease mechanism [80].

Oddi sphincter dysfunction is considered a possible cause of pancreatitis. In a randomized clinical trial including patients with recurrent idiopathic pancreatitis and manometry with sphincter dysfunction who were allocated for treatment with biliary sphincterotomy or biliary and pancreatic sphincterotomy, recurrence rates after treatment were $48.5 \%$ and $47.2 \%$ respectively (CI 95\%, -22.3 to 24.9, P 1.0 ) [81]. Although the treatment presented a similar response, the presence of manometry with dysfunction sphincter was an independent risk factor for recurrent AP.

\subsection{Etiology Evaluation}

The initial evaluation of the etiology of pancreatitis should begin with detailed anamnesis considering previous episodes of BP, history of biliary lithiasis, alcohol consumption, drugs, recent invasive procedures, known hyperlipidemia, family history of $\mathrm{BP}$, physical examination, laboratory tests including liver enzymes, calcium and triglycerides, and abdominal ultrasonography.

In patients considered idiopathic, endoscopic ultrasonography is recommended as the first step in the investigation of microlithiasis, neoplasia, and chronic pancreatitis. If not, it is recommended to carry out magnetic nuclear resonance cholangiography with secretin stimulation to identify rare morphological changes. Computed tomography of the abdomen should also be performed. If the etiology remains unidentified, especially after a second idiopathic episode, genetic counseling should be considered [82].

In a single episode of indeterminate AP in young patients ( $<35$ years) and recurrent undetermined $\mathrm{AP}$, a study demonstrated the presence of pathological variants in the CFTR, PRSS1, SPINK1 and CTRC genes in $47.8 \%$ of the cases. In this group of patients, early genetic testing should be performed. In patients with a mutation of the CFTR gene, one should consider screening for surgical fibrosis with a sweat test [83].

When autoimmune pancreatitis is suspected after initial imaging, the presence of another identified etiology that may be responsible for the condition should be considered. If not, try to identify which subtype is likely, whether type 1 or type 2, according to the presence of involvement of other organs, serum IgG4 level and presence of concomitant inflammatory bowel disease. In cases where the diagnosis of the subtype is unclear, a thin-needle biopsy should be performed to exclude malignancy. Therapy with corticosteroids should only be performed after exclusion of this possibility [60].

\subsection{Recurrence}


In a 20-year study, recurrent acute pancreatitis (RAP) occurred in $16.5 \%$ of the patients. The annual recurrence rate was $5.3 \%, 1.5 \%, 0.6 \%$, and $1.9 \%$ respectively for patients with AP alcohol, biliary, idiopathic and hypertriglyceridemia [84]. The importance of determining the etiology lies in the treatment of the causal factor in order to avoid new episodes of the disease.

New episodes of ABP may be avoided with cholecystectomy as soon as possible, preferably in the same in hospitalization. In a meta-analysis, evaluating the safety of cholecystectomy after an episode of mild ABP, patients who were submitted to interval cholecystectomy (after 40 days) were readmitted to hospital in $18 \%$ of cases due to biliary events, with AP in $45 \%$, acute cholecystitis in $18 \%$ and biliary colic in 37\% [85]. Patients who underwent cholecystectomy at the same hospital did not present any recurrence.

Patients with AAP should be referred for continued follow-up outside the hospital environment with the objective of alcohol abstention. A randomized controlled trial demonstrated that the risk of recurrence after the first episode of AAP significantly reduced following counseling against alcohol consumption [86].

Patients with BP due to hypertriglyceridemia should be advised about changes in lifestyle directed to weight loss, limiting consumption of fats and simple carbohydrates, alcohol abstention, and control of secondary risk factors such as diabetes control . Fibrates are the first - line drugs to treat hypertriglyceridemia [51].

Patients with genetic causes should stop smoking and alcohol consumption to prevent progression to chronic pancreatitis and reduce the risk of neoplasia. The identified mutation cation can also help to select candidate patients for targeted therapies under investigation, as modulators of CFTR and calcium channel blockers for PRSS1 mutations still under study but with the potential to prevent and treat symptoms progression disease [86,87].

Corticosteroids are the first line of treatment for patients with active autoimmune pancreatitis presenting a response rate greater than $95 \%$. After remission therapy, for 4 weeks, further imaging should be done to track response. Maintenance therapy may be considered in type 1 patients with a high recurrence risk such as involvement of the proximal biliary tract, diffuse pancreas enlargement, persistently increased levels of IgG4 after use of corticoids, delayed radiographic remission, and disease involving 2 or more organs. Patients of type 2 present a high risk of recurrence and are generally not indicated for maintenance therapy $[51,88,89]$.

\section{Conclusions}

The result of this meta-analysis confirms the expectation of the high frequency of ABP, especially in Latin America, which presents a distinct etiological profile, associated with the low frequency of AAP. The assessment diagnostic should be performed to exclude bile because, in the case of AP, starting with dosing transaminases (AST and ALT) and abdominal ultrasound. Often, depending on the limitations of the method, the sensitivity of abdominal ultrasound is reduced. In these cases it is important to consider repeating the ultrasound after clinical improvement and, if negative, endoscopic ultrasonography.

It is important to note that large population studies, despite their capacity to offer data and a very significant number of patients, seem to present less accurate results, an approximation of reality that must be interpreted with caution. In studies with medical records, the cases of BP that remain without etiological classification are around $16 \%$, a proportion considered adequate, but the challenge remains to reduce these cases more and make possible the treatment of the cause decrease the cases of pancreatitis recurrent. 
Analysis and interpretation, Drafting and Critical revision of the Article: Roberto Carlos, Mariana Zilio, Almeida Lucas, Albert Fernando, Arianna Costas

Final approval of the article: Roberto Carlos, Mariana Zilio, Almeida Lucas, Albert Fernando, Arianna Costas

Funding: No funding to disclose

Acknowledgments: None

Conflicts of Interest: The authors declare no conflict of interest.

\section{References}

1. Yang, A.L. Epidemiology of Alcohol-Related Liver and Pancreatic Disease in the United States. Archives of Internal Medicine 2008, 168, 649, doi:10.1001/archinte.168.6.649.

2. Forsmark, C.E.; Baillie, J. AGA Institute Technical Review on Acute Pancreatitis. Gastroenterology 2007, 132, 2022-2044, doi:10.1053/j.gastro.2007.03.065.

3. Yadav, D.; Lowenfels, A.B. Trends in the Epidemiology of the First Attack of Acute Pancreatitis. Pancreas 2006, 33, 323-330, doi:10.1097/01.mpa.0000236733.31617.52.

4. Roberts, S.E.; Morrison-Rees, S.; John, A.; Williams, J.G.; Brown, T.H.; Samuel, D.G. The incidence and aetiology of acute pancreatitis across Europe. Pancreatology 2017, 17, 155-165, doi:10.1016/j.pan.2017.01.005.

5. Zilio, M.B.; Eyff, T.F.; Azeredo-Da-Silva, A.L.F.; Bersch, V.P.; Osvaldt, A.B. A systematic review and meta-analysis of the aetiology of acute pancreatitis. HPB 2018, 10.1016/j.hpb.2018.08.003, doi:10.1016/j.hpb.2018.08.003.

6. Xiao, A.Y.; Tan, M.L.Y.; Wu, L.M.; Asrani, V.M.; Windsor, J.A.; Yadav, D.; Petrov, M.S. Global incidence and mortality of pancreatic diseases: a systematic review, meta-analysis, and metaregression of population-based cohort studies. The Lancet Gastroenterology \& Hepatology 2016, 1, 4555, doi:10.1016/s2468-1253(16)30004-8.

7. Yadav, D.; O'Connell, M.; Papachristou, G.I. Natural History Following the First Attack of Acute Pancreatitis. The American Journal of Gastroenterology 2012, 107, 1096-1103, doi:10.1038/ajg.2012.126.

8. Spanier, B.W.M.; Dijkgraaf, M.G.W.; Bruno, M.J. Epidemiology, aetiology and outcome of acute and chronic pancreatitis: An update. Best Practice E Research Clinical Gastroenterology 2008, 22, 45-63, doi:10.1016/j.bpg.2007.10.007.

9. Zheng, Y.; Zhou, Z.; Li, H.; Li, J.; Li, A.; Ma, B.; Zhang, T.; Liao, Q.; Ye, Y.; Zhang, Z., et al. A Multicenter Study on Etiology of Acute Pancreatitis in Beijing During 5 Years. Pancreas 2014, 10.1097/mpa.0000000000000273, 1, doi:10.1097/mpa.0000000000000273.

10. Disease, G.B.D.; Injury, I.; Prevalence, C. Global, regional, and national incidence, prevalence, and years lived with disability for 328 diseases and injuries for 195 countries, 1990-2016: a systematic analysis for the Global Burden of Disease Study 2016. Lancet 2017, 390, 1211-1259, doi:10.1016/S01406736(17)32154-2.

11. O'Farrell, A.; Allwright, S.; Toomey, D.; Bedford, D.; Conlon, K. Hospital admission for acute pancreatitis in the Irish population, 1997 2004: could the increase be due to an increase in alcoholrelated pancreatitis? Journal of Public Health 2007, 29, 398-404, doi:10.1093/pubmed/fdm069.

12. Kickbusch, I. BRICS' contributions to the global health agenda. Bulletin of the World Health Organization 2014, 92, 463-464, doi:10.2471/blt.13.127944. 
13. Yadav, D.; Lowenfels, A.B. The Epidemiology of Pancreatitis and Pancreatic Cancer. Gastroenterology 2013, 144, 1252-1261, doi:10.1053/j.gastro.2013.01.068.

14. Yadav, D.; Ng, B.; Saul, M.; Kennard, E.D. Relationship of Serum Pancreatic Enzyme Testing Trends With the Diagnosis of Acute Pancreatitis. Pancreas 2011, 40, 383-389, doi:10.1097/mpa.0b013e3182062970.

15. Forsmark, C.E.; Swaroop Vege, S.; Wilcox, C.M. Acute Pancreatitis. New England Journal of Medicine 2016, 375, 1972-1981, doi:10.1056/nejmra1505202.

16. Shah, A.P.; Mourad, M.M.; Bramhall, S.R. Acute pancreatitis: current perspectives on diagnosis and management. Journal of inflammation research 2018, 11, 77-85, doi:10.2147/JIR.S135751.

17. Wang, G.-J.; Gao, C.-F.; Wei, D.; Wang, C.; Ding, S.-Q. Acute pancreatitis: Etiology and common pathogenesis. World Journal of Gastroenterology 2009, 15, 1427, doi:10.3748/wjg.15.1427.

18. Gukovsky, I.; Pandol, S.J.; Mareninova, O.A.; Shalbueva, N.; Jia, W.; Gukovskaya, A.S. Impaired autophagy and organellar dysfunction in pancreatitis. Journal of Gastroenterology and Hepatology 2012, 27, 27-32, doi:10.1111/j.1440-1746.2011.07004.x.

19. Dawra, R.; Sah, R.P.; Dudeja, V.; Rishi, L.; Talukdar, R.; Garg, P.; Saluja, A.K. Intra-acinar Trypsinogen Activation Mediates Early Stages of Pancreatic Injury but Not Inflammation in Mice With Acute Pancreatitis. Gastroenterology 2011, 141, 2210-2217.e2212, doi:10.1053/j.gastro.2011.08.033.

20. Apte, M.V.; Wilson, J.S.; Korsten, M.A.; McCaughan, G.W.; Haber, P.S.; Pirola, R.C. Effects of ethanol and protein deficiency on pancreatic digestive and lysosomal enzymes. Gut 1995, 36, 287-293, doi:10.1136/gut.36.2.287.

21. Apte, M.V.; Pirola, R.C.; Wilson, J.S. Mechanisms of alcoholic pancreatitis. Journal of Gastroenterology and Hepatology 2010, 25, 1816-1826, doi:10.1111/j.1440-1746.2010.06445.x.

22. Lankisch, P.G.; Apte, M.; Banks, P.A. Acute pancreatitis. The Lancet 2015, 386, 85-96, doi:10.1016/s0140-6736(14)60649-8.

23. Sutton, R.; Petersen, O.H.; Pandol, S.J. Pancreatitis and Calcium Signalling. Pancreas 2008, 36, e1-e14, doi:10.1097/mpa.0b013e3181675010.

24. Lévy, P.; Boruchowicz, A.; Hastier, P.; Pariente, A.; Thévenot, T.; Frossard, J.L.; Buscail, L.; Mauvais, F.; Duchmann, J.C.; Courrier, A., et al. Diagnostic criteria in predicting a biliary origin of acute pancreatitis in the era of endoscopic ultrasound: Multicentre prospective evaluation of 213 patients. Pancreatology 2005, 5, 450-456, doi:10.1159/000086547.

25. Fracchia, M. Biliary lipid composition in cholesterol microlithiasis. Gut 2001, 48, 702-706, doi:10.1136/gut.48.5.702.

26. Shaffer, E.A. Epidemiology of gallbladder stone disease. Best Practice \& Research Clinical Gastroenterology 2006, 20, 981-996, doi:10.1016/j.bpg.2006.05.004.

27. Stinton, L.M.; Shaffer, E.A. Epidemiology of Gallbladder Disease: Cholelithiasis and Cancer. Gut and Liver 2012, 6, 172-187, doi:10.5009/gnl.2012.6.2.172.

28. Rawla, P.; Thandra, K.C.; Sunkara, T. Pancreatic cancer and obesity: epidemiology, mechanism, and preventive strategies. Clinical journal of gastroenterology 2019, 10.1007/s12328-019-00953-3, doi:10.1007/s12328-019-00953-3.

29. Tenner, S.; Dubner, H.; Steinberg, W. Predicting gallstone pancreatitis with laboratory parameters: a meta-analysis. Am J Gastroenterol 1994, 89, 1863-1866.

30. Strasberg, S.M. Acute Calculous Cholecystitis. New England Journal of Medicine 2008, 358, 2804-2811, doi:10.1056/nejmcp0800929. 
31. Tandon, M.; Topazian, M. Endoscopic ultrasound in idiopathic acute pancreatitis. The American Journal of Gastroenterology 2001, 96, 705-709, doi:10.1111/j.1572-0241.2001.03609.x.

32. Wilcox, C.M.; Seay, T.; Kim, H.; Varadarajulu, S. Prospective Endoscopic Ultrasound-Based Approach to the Evaluation of Idiopathic Pancreatitis: Causes, Response to Therapy, and Long-term Outcome. Am J Gastroenterol 2016, 111, 1339-1348, doi:10.1038/ajg.2016.240.

33. Samokhvalov, A.V.; Rehm, J.; Roerecke, M. Alcohol Consumption as a Risk Factor for Acute and Chronic Pancreatitis: A Systematic Review and a Series of Meta-analyses. EBioMedicine 2015, 2, 19962002, doi:10.1016/j.ebiom.2015.11.023.

34. Coté, G.A.; Yadav, D.; Slivka, A.; Hawes, R.H.; Anderson, M.A.; Burton, F.R.; Brand, R.E.; Banks, P.A.; Lewis, M.D.; Disario, J.A., et al. Alcohol and Smoking as Risk Factors in an Epidemiology Study of Patients With Chronic Pancreatitis. Clinical Gastroenterology and Hepatology 2011, 9, 266-273, doi:10.1016/j.cgh.2010.10.015.

35. Kristiansen, L.; Gronbaek, M.; Becker, U.; Tolstrup, J.S. Risk of Pancreatitis According to Alcohol Drinking Habits: A Population-based Cohort Study. American Journal of Epidemiology 2008, 168, $932-$ 937, doi:10.1093/aje/kwn222.

36. Phillip, V.; Huber, W.; Hagemes, F.; Lorenz, S.; Matheis, U.; Preinfalk, S.; Schuster, T.; Lippl, F.; Saugel, B.; Schmid, R.M. Incidence of Acute Pancreatitis Does Not Increase During Oktoberfest, but Is Higher Than Previously Described in Germany. Clinical Gastroenterology and Hepatology 2011, 9 , 995-1000.e1003, doi:10.1016/j.cgh.2011.06.016.

37. Sadr Azodi, O.; Orsini, N.; Andrén-Sandberg, Å.; Wolk, A. Effect of type of alcoholic beverage in causing acute pancreatitis. British Journal of Surgery 2011, 98, 1609-1616, doi:10.1002/bjs.7632.

38. Schmidt, D.N. Apparent risk factors for chronic and acute pancreatitis in Stockholm county. Spirits but not wine and beer. International journal of pancreatology : official journal of the International Association of Pancreatology 1991, 8, 45-50.

39. Whitcomb, D.C. Genetic Risk Factors for Pancreatic Disorders. Gastroenterology 2013, 144, 1292-1302, doi:10.1053/j.gastro.2013.01.069.

40. Lankisch, P.G.; Lowenfels, A.B.; Maisonneuve, P. What is the Risk of Alcoholic Pancreatitis in Heavy Drinkers? Pancreas 2002, 25, 411-412, doi:10.1097/00006676-200211000-00015.

41. Aktas, H.; de Ridder, L.; Haringsma, J.; Kuipers, E.; Mensink, P. Complications of single-balloon enteroscopy: a prospective evaluation of 166 procedures. Endoscopy 2010, 42, 365-368, doi:10.1055/s0029-1243931.

42. Aliperti, G. Complications Related to Diagnostic and Therapeutic Endoscopic Retrograde Cholangiopancreatography. Gastrointestinal Endoscopy Clinics of North America 1996, 6, 379-407, doi:10.1016/s1052-5157(18)30368-4.

43. Dumonceau, J.-M.; Andriulli, A.; Elmunzer, B.; Mariani, A.; Meister, T.; Deviere, J.; Marek, T.; Baron, T.; Hassan, C.; Testoni, P., et al. Prophylaxis of post-ERCP pancreatitis: European Society of Gastrointestinal Endoscopy (ESGE) Guideline - Updated June 2014. Endoscopy 2014, 46, 799-815, doi:10.1055/s-0034-1377875.

44. Kahaleh, M.; Freeman, M. Prevention and Management of Post-Endoscopic Retrograde Cholangiopancreatography Complications. Clinical Endoscopy 2012, 45, 305, doi:10.5946/ce.2012.45.3.305.

45. Hou, Y.-C.; Hu, Q.; Huang, J.; Fang, J.-Y.; Xiong, H. Efficacy and safety of rectal nonsteroidal antiinflammatory drugs for prophylaxis against post-ERCP pancreatitis: a systematic review and metaanalysis. Scientific Reports 2017, 7, doi:10.1038/srep46650. 
46. Toskes, P.P. How to Position Exocrine and Endocrine Function Tests in the Diagnostic Approach to Chronic Pancreatitis. In Chronic Pancreatitis, Springer Berlin Heidelberg: 1990; 10.1007/978-3-64275319-0_38pp 302-308.

47. Uhl, W.; Warshaw, A.; Imrie, C.; Bassi, C.; McKay, C.J.; Lankisch, P.G.; Carter, R.; Magno, E.D.; Banks, P.A.; Whitcomb, D.C., et al. IAP Guidelines for the surgical management of acute pancreatitis. Pancreatology 2002, 2, 565-573, doi:10.1159/000067684.

48. Rawla, P.; Sunkara, T.; Thandra, K.C.; Gaduputi, V. Hypertriglyceridemia-induced pancreatitis: updated review of current treatment and preventive strategies. Clinical journal of gastroenterology 2018, 11, 441-448, doi:10.1007/s12328-018-0881-1.

49. Lindkvist, B.; Appelros, S.; Regnér, S.; Manjer, J. A prospective cohort study on risk of acute pancreatitis related to serum triglycerides, cholesterol and fasting glucose. Pancreatology 2012, 12, 317-324, doi:10.1016/j.pan.2012.05.002.

50. Yadav, D.; Pitchumoni, C.S. Issues in Hyperlipidemic Pancreatitis. Journal of Clinical Gastroenterology 2003, 36, 54-62, doi:10.1097/00004836-200301000-00016.

51. Scherer, J.; Singh, V.P.; Pitchumoni, C.S.; Yadav, D. Issues in Hypertriglyceridemic Pancreatitis. Journal of Clinical Gastroenterology 2014, 48, 195-203, doi:10.1097/01.mcg.0000436438.60145.5a.

52. Truninger, K.; Schmid, P.A.; Hoffmann, M.M.; Bertschinger, P.; Ammann, R.W. Recurrent Acute and Chronic Pancreatitis in Two Brothers With Familial Chylomicronemia Syndrome. Pancreas 2006, 32, 215-219, doi:10.1097/01.mpa.0000202942.93578.dd.

53. Whitcomb, D.C.; Gorry, M.C.; Preston, R.A.; Furey, W.; Sossenheimer, M.J.; Ulrich, C.D.; Martin, S.P.; Gates, L.K.; Amann, S.T.; Toskes, P.P., et al. Hereditary pancreatitis is caused by a mutation in the cationic trypsinogen gene. Nature Genetics 1996, 14, 141-145, doi:10.1038/ng1096-141.

54. Howes, N.; Lerch, M.M.; Greenhalf, W.; Stocken, D.D.; Ellis, I.; Simon, P.; Truninger, K.; Ammann, R.; Cavallini, G.; Charnley, R.M., et al. Clinical and genetic characteristics of hereditary pancreatitis in Europe. Clinical Gastroenterology and Hepatology 2004, 2, 252-261, doi:10.1016/s1542-3565(04)000138.

55. Rebours, V.; Boutron-Ruault, M.-C.; Schnee, M.; Férec, C.; Maire, F.; Hammel, P.; Ruszniewski, P.; Lévy, P. Risk of Pancreatic Adenocarcinoma in Patients With Hereditary Pancreatitis: A National Exhaustive Series. The American Journal of Gastroenterology 2008, 103, 111-119, doi:10.1111/j.15720241.2007.01597.x.

56. Correction: Mechanisms of CFTR Functional Variants That Impair Regulated Bicarbonate Permeation and Increase Risk for Pancreatitis but Not for Cystic Fibrosis. PLoS Genetics 2014, 10, e1004778, doi:10.1371/journal.pgen.1004778.

57. Rosendahl, J.; Witt, H.; Szmola, R.; Bhatia, E.; Ózsvári, B.; Landt, O.; Schulz, H.-U.; Gress, T.M.; Pfützer, R.; Löhr, M., et al. Chymotrypsin C (CTRC) variants that diminish activity or secretion are associated with chronic pancreatitis. Nature Genetics 2007, 40, 78-82, doi:10.1038/ng.2007.44.

58. LaRusch, J.; Jung, J.; General, I.J.; Lewis, M.D.; Park, H.W.; Brand, R.E.; Gelrud, A.; Anderson, M.A.; Banks, P.A.; Conwell, D., et al. Mechanisms of CFTR functional variants that impair regulated bicarbonate permeation and increase risk for pancreatitis but not for cystic fibrosis. PLoS Genet 2014, 10, e1004376, doi:10.1371/journal.pgen.1004376.

59. Sah, R.P.; Pannala, R.; Chari, S.T.; Sugumar, A.; Clain, J.E.; Levy, M.J.; Pearson, R.K.; Smyrk, T.C.; Petersen, B.T.; Topazian, M.D., et al. Prevalence, Diagnosis, and Profile of Autoimmune Pancreatitis Presenting with Features of Acute or Chronic Pancreatitis. Clinical Gastroenterology and Hepatology 2010, 8, 91-96, doi:10.1016/j.cgh.2009.09.024. 
60. Hart, P.A.; Krishna, S.G.; Okazaki, K. Diagnosis and Management of Autoimmune Pancreatitis. Current Treatment Options in Gastroenterology 2017, 15, 538-547, doi:10.1007/s11938-017-0147-x.

61. Martínez-de-Alegría, A.; Baleato-González, S.; García-Figueiras, R.; Bermúdez-Naveira, A.; Abdulkader-Nallib, I.; Díaz-Peromingo, J.A.; Villalba-Martín, C. IgG4-related Disease from Head to Toe. RadioGraphics 2015, 35, 2007-2025, doi:10.1148/rg.357150066.

62. Nitsche, C.; Maertin, S.; Scheiber, J.; Ritter, C.A.; Lerch, M.M.; Mayerle, J. Drug-Induced Pancreatitis. Current Gastroenterology Reports 2012, 14, 131-138, doi:10.1007/s11894-012-0245-9.

63. Jones, M.R.; Hall, O.M.; Kaye, A.M.; Kaye, A.D. Drug-induced acute pancreatitis: a review. The Ochsner journal 2015, 15, 45-51.

64. Badalov, N.; Baradarian, R.; Iswara, K.; Li, J.; Steinberg, W.; Tenner, S. Drug-Induced Acute Pancreatitis: An Evidence-Based Review. Clinical Gastroenterology and Hepatology 2007, 5, 648661.e643, doi:10.1016/j.cgh.2006.11.023.

65. Rawla, P.; Raj, J.P. Doxycycline-Induced Acute Pancreatitis: A Rare Adverse Event. Gastroenterology Res 2017, 10, 244-246, doi:10.14740/gr838w.

66. Mithöfer, K.; Fernández-Del Castillo, C.; Frick, T.W.; Lewandrowski, K.B.; Rattner, D.W.; Warshaw, A.L. Acute hypercalcemia causes acute pancreatitis and ectopic trypsinogen activation in the rat. Gastroenterology 1995, 109, 239-246, doi:10.1016/0016-5085(95)90290-2.

67. Felderbauer, P.; Karakas, E.; Fendrich, V.; Bulut, K.; Horn, T.; Lebert, R.; Holland-Letz, T.; Schmitz, F.; Bartsch, D.; Schmidt, W.E. Pancreatitis Risk in Primary Hyperparathyroidism: Relation to Mutations in the SPINK1 Trypsin Inhibitor (N34S) and the Cystic Fibrosis Gene. The American Journal of Gastroenterology 2008, 103, 368-374, doi:10.1111/j.1572-0241.2007.01695.x.

68. Felderbauer, P.; Karakas, E.; Fendrich, V.; Lebert, R.; Bartsch, D.K.; Bulut, K. Multifactorial Genesis of Pancreatitis in Primary Hyperparathyroidism: Evidence for "Protective" (PRSS2) and “Destructive” (CTRC) Genetic Factors. Experimental and Clinical Endocrinology \& Diabetes 2010, 119, 26-29, doi:10.1055/s-0030-1255106.

69. Khoo, T.K.; Vege, S.S.; Abu-Lebdeh, H.S.; Ryu, E.; Nadeem, S.; Wermers, R.A. Acute Pancreatitis in Primary Hyperparathyroidism: A Population-Based Study. The Journal of Clinical Endocrinology $\mathcal{E}$ Metabolism 2009, 94, 2115-2118, doi:10.1210/jc.2008-1965.

70. Bess, M.A. Hyperparathyroidism and Pancreatitis. JAMA 1980, 243, 246, doi:10.1001/jama.1980.03300290028015.

71. Sunkara, T.; Caughey, M.E.; Rawla, P.; Yarlagadda, K.S.; Gaduputi, V. Severe Acute Pancreatitis as an Index Clinical Manifestation of Parathyroid Adenoma. Cureus 2018, 10, e2445, doi:10.7759/cureus.2445.

72. DiMagno, M.J.; DiMagno, E.P. Editorial: Pancreas Divisum Does Not Cause Pancreatitis, But Associates With CFTR Mutations. American Journal of Gastroenterology 2012, 107, 318-320, doi:10.1038/ajg.2011.430.

73. Bertin, C.; Pelletier, A.-L.; Vullierme, M.P.; Bienvenu, T.; Rebours, V.; Hentic, O.; Maire, F.; Hammel, P.; Vilgrain, V.; Ruszniewski, P., et al. Pancreas Divisum Is Not a Cause of Pancreatitis by Itself But Acts as a Partner of Genetic Mutations. American Journal of Gastroenterology 2012, 107, 311-317, doi:10.1038/ajg.2011.424.

74. Rawla, P.; Bandaru, S.S.; Vellipuram, A.R. Review of Infectious Etiology of Acute Pancreatitis. Gastroenterology Research 2017, 10, 153-158, doi:10.14740/gr858w.

75. Parenti, D.M.; Steinberg, W.; Kang, P. Infectious Causes of Acute Pancreatitis. Pancreas 1996, 13, 356371, doi:10.1097/00006676-199611000-00005. 
76. Tomaszewska, R.; Dembinski, A.; Warzecha, Z.; Ceranowicz, P.; Stachura, J. Morphological changes and morphological-functional correlations in acute experimantal ischemia/reperfusion pancreatitis in rats. An important role of tubular complexes formation. Gastroenterology 2000, 118, A1156, doi:10.1016/s0016-5085(00)80441-2.

77. Wang, Q.; Shen, M.; Leng, X.; Zeng, X.; Zhang, F.; Qian, J. Prevalence, severity, and clinical features of acute and chronic pancreatitis in patients with systemic lupus erythematosus. Rheumatology International 2016, 36, 1413-1419, doi:10.1007/s00296-016-3526-z.

78. Moolenaar, W.; Lamers, C.B.H.W. Cholesterol crystal embolization to liver, gallbladder, and pancreas. Digestive Diseases and Sciences 1996, 41, 1819-1822, doi:10.1007/bf02088752.

79. Warshaw, A.L.; O'Hara, P.J. Susceptibility of the Pancreas to Ischemic Injury in Shock. Annals of Surgery 1978, 188, 197-201, doi:10.1097/00000658-197808000-00012.

80. Patel, R.S.; Johlin, F.C.; Murray, J.A. Celiac disease and recurrent pancreatitis. Gastrointestinal Endoscopy 1999, 50, 823-827, doi:10.1016/s0016-5107(99)70166-5.

81. Coté, G.A.; Imperiale, T.F.; Schmidt, S.E.; Fogel, E.; Lehman, G.; McHenry, L.; Watkins, J.; Sherman, S. Similar Efficacies of Biliary, With or Without Pancreatic, Sphincterotomy in Treatment of Idiopathic Recurrent Acute Pancreatitis. Gastroenterology 2012, 143, 1502-1509.e1501, doi:10.1053/j.gastro.2012.09.006.

82. Working Group, I.A.P.A.P.A.A.P.G. IAP/APA evidence-based guidelines for the management of acute pancreatitis. Pancreatology 2013, 13, e1-15, doi:10.1016/j.pan.2013.07.063.

83. Jalaly, N.Y.; Moran, R.A.; Fargahi, F.; Khashab, M.A.; Kamal, A.; Lennon, A.M.; Walsh, C.; Makary, M.A.; Whitcomb, D.C.; Yadav, D., et al. An Evaluation of Factors Associated With Pathogenic PRSS1, SPINK1, CTFR, and/or CTRC Genetic Variants in Patients With Idiopathic Pancreatitis. The American Journal of Gastroenterology 2017, 112, 1320-1329, doi:10.1038/ajg.2017.106.

84. Lankisch, P.G.; Breuer, N.; Bruns, A.; Weber-Dany, B.; Lowenfels, A.B.; Maisonneuve, P. Natural History of Acute Pancreatitis: A Long-Term Population-Based Study. The American Journal of Gastroenterology 2009, 104, 2797-2805, doi:10.1038/ajg.2009.405.

85. van Baal, M.C.; Besselink, M.G.; Bakker, O.J.; van Santvoort, H.C.; Schaapherder, A.F.; Nieuwenhuijs, V.B.; Gooszen, H.G.; van Ramshorst, B.; Boerma, D. Timing of Cholecystectomy After Mild Biliary Pancreatitis. Annals of Surgery 2012, 255, 860-866, doi:10.1097/sla.0b013e3182507646.

86. Nordback, I.; Pelli, H.; Lappalainen-Lehto, R.; Järvinen, S.; Räty, S.; Sand, J. The Recurrence of Acute Alcohol-Associated Pancreatitis Can Be Reduced: A Randomized Controlled Trial. Gastroenterology 2009, 136, 848-855, doi:10.1053/j.gastro.2008.11.044.

87. Morinville, V.D.; Lowe, M.E.; Elinoff, B.D.; Whitcomb, D.C. Hereditary Pancreatitis Amlodipine Trial. Pancreas 2007, 35, 308-312, doi:10.1097/mpa.0b013e318120023a.

88. Rowe, S.M.; Verkman, A.S. Cystic Fibrosis Transmembrane Regulator Correctors and Potentiators. Cold Spring Harbor Perspectives in Medicine 2013, 3, a009761-a009761, doi:10.1101/cshperspect.a009761.

89. Okazaki, K.; Chari, S.T.; Frulloni, L.; Lerch, M.M.; Kamisawa, T.; Kawa, S.; Kim, M.-H.; Lévy, P.; Masamune, A.; Webster, G., et al. International consensus for the treatment of autoimmune pancreatitis. Pancreatology 2017, 17, 1-6, doi:10.1016/j.pan.2016.12.003. 